\title{
Effect of cessation of short-term therapy with ipratropium bromide on lung function and airway responsiveness
}

\author{
P.J. Wilding, M.M. Clark, I.D. Pavord, D. Parker, J.A. Bennett, A.E. Tattersfield
}

\begin{abstract}
Effect of cessation of short-term therapy with ipratropium bromide on lung function and airway responsiveness. P.J. Wilding, M.M. Clark, I.D. Pavord, D. Parker, J.A. Bennett, A.E. Tattersfield. C)ERS Journals Ltd 1996.

ABSTRACT: Regular exposure to antimuscarinic drugs would be expected to upregulate airway muscarinic receptors and could cause a transient increase in airways obstruction if treatment was stopped or omitted. We have examined peak expiratory flow rate (PEFR) during treatment and forced expiratory flow in one second (FEV1) and airway responsiveness to three constrictor agonists (as the provocative dose of agonist causing a $20 \%$ fall in FEV1, (PD20)) following cessation of regular inhaled ipratropium bromide, in 13 subjects with mild stable asthma.

Subjects inhaled placebo and ipratropium bromide, $80 \mu \mathrm{g}$ q.i.d. for 14 days in a cross-over fashion with a 1 week run-in/wash-out period before and after each treatment period. Subjects recorded symptom scores and PEFR throughout the study, and FEV1 and PD20 to histamine, methacholine and metabisulphite were measured before and after cessation of treatment.

When compared to baseline, FEV1 was lower after cessation of ipratropium than after placebo, with a significant difference $30 \mathrm{~h}$ after the last dose (difference 190 $\mathrm{mL} ; 95 \%$ confidence interval $(95 \% \mathrm{CI}) 310-70 \mathrm{~mL} ; \mathrm{p}<0.02)$. FEV1 measured 6-10 days later, did not differ significantly. PEFR was significantly lower after cessation of ipratropium than after placebo on Day 15 (19-37 $\mathrm{h}$ after the last dose) (mean difference 4.6\%; 95\% CI 1.6-7.5\%; $\mathbf{p}<0.01$ ) but not on Day 16. There were no significant changes in PD20 histamine, methacholine and metabisulphite, symptom scores or rescue bronchodilator use after cessation of treatment.

Thus, transient bronchoconstriction was found around $30 \mathrm{~h}$ after cessation of regular therapy with inhaled ipratropium for 2 weeks. The mechanism is unclear, as no evidence of muscarinic receptor upregulation was found. Although the changes were small and unlikely to be important for most patients, the results of this study indicate that the timing of lung function measurements relative to the last dose of ipratropium is important when interpreting the course of lung function in long-term studies.

Eur Respir J., 1996, 9, 1627-1631.
\end{abstract}

Division of Respiratory Medicine, City Hospital, Nottingham, UK.

Correspondence: A.E. Tattersfield

Division of Respiratory Medicine

City Hospital

Hucknall Road

Nottingham NG5 1PB

UK

Keywords: Anti-muscarinic

asthma

ipratropium

lung function

Received: March 131995

Accepted after revision April 301996
Inhaled antimuscarinic drugs cause bronchodilatation by competing for airway muscarinic receptors with acetylcholine released from parasympathetic nerves. Drugs such as ipratropium bromide are thought to act predominantly on $\mathrm{M}_{3}$ receptors on airway smooth muscle, but they may have some additional effect on autoinhibitory $\mathrm{M}_{2}$ receptors on cholinergic nerves or on $\mathrm{M}_{1}$ receptors on autonomic ganglia [1].

Vagotomy and atropine cause upregulation of muscarinic receptors and an enhanced response to muscarinic stimuli in a variety of animal tissues ex-vivo [2-5]. Regular exposure to inhaled antimuscarinic drugs in man would be expected, therefore, to lead to upregulation of airway muscarinic receptors, causing increased responsiveness to muscarinic agonists when the drugs are withdrawn. The airways would then show increased responsiveness (known as denervation hypersensitivity) to exogenous muscarinic stimuli, such as methacholine, whilst the increased response to endogenous acetylcholine released from the vagus would cause bronchoconstriction. There is some support for this hypothesis, as transient supersensitivity to inhaled methacholine occurred following cessation of regular ipratropium in one uncontrolled trial [6], and lung function deteriorated following long-term inhaled ipratropium bromide in another [7]. Since this effect could be important clinically and in interpreting studies of longterm treatment with antimuscarinic drugs, we have looked at change in lung function during and after cessation of 2 weeks of therapy with inhaled ipratropium bromide in more detail in subjects with mild asthma. We have also looked at sensitivity to three inhaled constrictor agents before and after treatment, to determine whether there was evidence of muscarinic receptor upregulation. Histamine was used as a directly acting stimulus, methacholine as a muscarinic agonist and sodium metabisulphite as a stimulus of vagal pathways [8]. Muscarinic receptor upregulation would be expected to increase the responsiveness to methacholine and sodium metabisulphite but not to histamine. 
Table 1. - Baseline characteristics of subjects

\begin{tabular}{ccccccccl}
\hline $\begin{array}{c}\text { Subj } \\
\text { No. }\end{array}$ & $\begin{array}{c}\text { Age } \\
\text { yrs }\end{array}$ & Sex & $\begin{array}{c}\text { FEV1 } \\
\text { L }\end{array}$ & $\begin{array}{c}\text { FEV1 } \\
\% \text { pred }\end{array}$ & $\begin{array}{c}\text { PD20,Mch } \\
\mu \mathrm{M}\end{array}$ & $\begin{array}{c}\text { PD20,His } \\
\mu \mathrm{M}\end{array}$ & $\begin{array}{c}\text { PD20,MBS } \\
\mu \mathrm{M}\end{array}$ & Medication \\
\hline 1 & 28 & $\mathrm{M}$ & 5.1 & 110 & 0.37 & 0.72 & 1.15 & Salb p.r.n. \\
2 & 30 & $\mathrm{~F}$ & 2.9 & 94 & 0.95 & 0.42 & 4.80 & $\begin{array}{l}\text { BDP 200 } \mu \mathrm{g} \text { b.i.d. } \\
\text { Salb p.r.n. }\end{array}$ \\
3 & 36 & $\mathrm{M}$ & 3.4 & 79 & 5.60 & 4.60 & 7.00 & Salb p.r.n. \\
4 & 30 & $\mathrm{~F}$ & 3.6 & 100 & 2.05 & 1.31 & 5.60 & Salb p.r.n. \\
5 & 54 & $\mathrm{M}$ & 2.6 & 76 & 0.56 & 0.20 & 25.00 & Salb p.r.n. \\
6 & 20 & $\mathrm{~F}$ & 3.4 & 113 & 0.22 & 0.27 & 1.34 & Salb p.r.n. \\
7 & 24 & $\mathrm{~F}$ & 2.9 & 84 & 0.28 & 0.46 & 2.30 & Salb p.r.n. \\
8 & 39 & $\mathrm{M}$ & 2.8 & 71 & 0.36 & 0.27 & 2.80 & Salb p.r.n. \\
9 & 38 & $\mathrm{M}$ & 4.4 & 98 & 1.60 & 0.80 & 7.50 & Salb p.r.n. \\
10 & 24 & $\mathrm{~F}$ & 3.0 & 97 & 0.15 & 0.21 & 2.20 & Salb p.r.n. \\
11 & 32 & $\mathrm{M}$ & 3.5 & 76 & 0.06 & 0.07 & 0.50 & BDP 200 $\mu \mathrm{g}$ b.i.d. \\
& & & & & & & & Salb p.r.n. \\
12 & 36 & $\mathrm{M}$ & 2.9 & 85 & 0.27 & 0.18 & 2.40 & Salb p.r.n. \\
13 & 49 & $\mathrm{M}$ & 3.4 & 80 & 1.05 & 1.20 & 5.80 & BDP 200 $\mu$ b.i.d. \\
& & & & & & & & Salb p.r.n. \\
\hline
\end{tabular}

Subj: subject; M: male; F: female; FEV1: forced expiratory volume in one second; \% pred: percentage of predicted value; PD20: provocative dose of agonist causing a 20\% decrease in FEV1; BDP: beclomethasone dipropionate; Salb: salbutamol; PD20,Mch: PD20 methacholine; PD20,His: PD20 histamine; PD20,MBS: PD20 metabisulphate.

\section{Methods}

\section{Subjects}

Thirteen nonsmoking subjects ( 5 females and 8 males aged 20-54 yrs) were recruited (table 1). Subjects had: a forced expiratory volume in one second (FEV1) of $70 \%$ predicted or more; an increase in FEV1, of at least $15 \%$ after inhaled salbutamol $400 \mu \mathrm{g}$; a dose of methacholine causing a $20 \%$ fall in FEV1 (PD20) of $6 \mu \mathrm{M}$ or less; and positive skin tests to at least two commonly tested allergens. Subjects were receiving no treatment other than an occasional dose of inhaled $\beta$-agonist (all subjects) and low-dose inhaled corticosteroids (three subjects), and all had stable asthma with no exacerbation of their symptoms or respiratory tract infection in the 6 weeks prior to the study. Subjects gave written informed consent to the study, which was approved by the Nottingham City Hospital Ethics Committee.

\section{Measurements}

FEV1 was measured by dry bellows spirometer (Vitalograph®; Vitalograph Ltd, Bucks, UK) as the higher of two measurements within $100 \mathrm{~mL}$. Peak expiratory flow rate (PEFR) was measured as the best of three readings using a mini-Wright peak flow meter (Airmed, UK). Airway responsiveness was measured using a breath-activated dosimeter (Mefar dosimeter MB3; Mefar S.R.L., Bovezzo, Italy), with subjects inhaling from functional residual capacity (FRC) to total lung capacity (TLC) (inhalation time $1 \mathrm{~s}$, pause time $6 \mathrm{~s}$, pressure $152 \mathrm{kPa}$ delivering $10-11 \mu \mathrm{L} \cdot$ puff- $\left.^{-1}\right)$. Subjects inhaled three puffs of saline, followed by 1-4 puffs of methacholine, histamine or sodium metabisulphite as needed to achieve doubling dose increments in the dose ranges of 0.02-42.9 $\mu \mathrm{M}$ for methacholine and histamine and 0.03-136 $\mu \mathrm{M}$ for metabisulphite. FEV1 was measured 2 min after each dose, and the test was stopped when FEV 1 had fallen by $20 \%$ from the postsaline value. PD20 was calculated by linear interpolation of the last two readings on the log dose-response plot.

Subjects kept diary cards throughout the study, including the run-in and wash-out periods, recording PEFR twice daily before treatment, rescue bronchodilator use and symptom scores for morning cough and wheeze and daytime breathlessness and wheeze (each on a five point scale: $0=$ no symptoms to $4=$ severe symptoms).

\section{Protocol}

This was a double-blind, randomized, cross-over study, in which subjects inhaled from identical metered-dose inhalers containing placebo and ipratropium bromide (Atrovent Forte $\AA$; Boehringer Ingelheim) $80 \mu \mathrm{g}$ four times a day for 2 weeks in randomized order, with a 1 week run-in/wash-out period prior to and after each treatment period. Subjects used the short-acting $\beta$-agonist, rimiterol hydrobromide (Pulmadil@; 3M) for symptom relief throughout the study but not within $2 \mathrm{~h}$ of a visit. The doses of inhaled corticosteroids used by three subjects were kept constant throughout the study, as was the timing of measurements for each subject. On Day 1 of each treatment period, subjects attended for measurement of FEV1, and a histamine challenge, followed $1 \mathrm{~h}$ after completion of the histamine challenge by a methacholine challenge. Subjects returned 6-8 h later for measurement of FEV1, and a metabisulphite challenge.

Subjects then started their study medication, with instructions to take two puffs four times daily and to take the last dose on the morning of Day 14. On Day 15, starting $24 \mathrm{~h}$ after the last dose of placebo/ipratropium, the sequence of FEV1 measurements and histamine and methacholine challenge was repeated in the morning, followed 6-8 h later by measurement of FEV1 and a metabisulphite challenge. Subjects reattended for a further measurement of FEV1 on the morning and afternoon of Day 16 and in the morning 6-10 days later at the end of the second wash-out period. Subjects increased the frequency of PEFR recordings to 4 hourly during waking hours for 2 days prior to and 3 days after the last dose of placebo/ipratropium. 
The study design gave $95 \%$ power to detect a difference in FEV1 of $84 \mathrm{~mL}$, and $80 \%$ power to detect a difference in airway responsiveness of one doubling dose with 12 subjects, according to previous studies [9-11].

\section{Analysis}

PD20 values were log transformed prior to analysis and are expressed as geometric mean values. Change in PD20 was measured in doubling doses of constrictor agonist [12]. Analysis of variance (ANOVA) was used, according to ARmitage [13], to determine whether there was any period or order effect of treatment and to compare baseline values for FEV1 (a.m. and p.m.) and PD20 histamine, methacholine and metabisulphite on Day 1 of each treatment period. Change from baseline values in PEFR during treatment and FEV1 (a.m. and p.m. on Days 15 and 16) and PD20 histamine, methacholine and metabisulphite after treatment were compared by paired t-test.

Four hourly measurements of PEFR were put into six hourly time windows (04:00-10:00, 10:00-16:00,

Table 2. - Baseline values of FEV 1 , PEFR and PD20 histamine, methacholine and metabisulphate before placebo and ipratropium

\begin{tabular}{|c|c|c|c|}
\hline & & Placebo & Ipratropium \\
\hline \multirow[t]{2}{*}{ PEFR $\mathrm{L} \cdot \mathrm{min}^{-1}$} & a.m. & $516(41)$ & $510(46)$ \\
\hline & p.m. & $531(43)$ & 519 (39) \\
\hline \multirow[t]{2}{*}{ FEV1 L } & a.m. & $3.26(0.7)$ & $3.21(0.49)$ \\
\hline & p.m. & $3.31(0.71)$ & $3.40(0.57)$ \\
\hline \multirow[t]{3}{*}{ PD20* $\mu \mathrm{M}$} & Histamine & $0.41(0.53)$ & $0.35(0.52)$ \\
\hline & Methacholine & $0.50(0.66)$ & $0.35(0.56)$ \\
\hline & Metabisulphate & $3.16(0.53)$ & $3.89(0.53)$ \\
\hline
\end{tabular}

Values are presented as mean, and SD in parenthesis. *: geometric mean, with SD in parenthesis, in doubling doses. PEFR: peak expiratory flow rate. For further abbreviations see legend to table 1.
16:00-22:00) as a mean recording for each subject within the time window, and compared between groups on Days 15 and 16 by area under the PEFR versus time curve. The 22:00-04:00 h time window was not used as there were few recordings. Symptom scores and use of rimiterol were compared after withdrawal from placebo and ipratropium using the Wilcoxon ranked sum test. Mean values are given with $95 \%$ confidence intervals (95\% CI). A p value of 0.05 was considered to be statistically significant.

\section{Results}

Four of the 13 subjects were withdrawn; two developed an upper respiratory tract infection (one on ipratropium and one on placebo); one for personal reasons; and one for noncompliance with visits. There were no treatment order or period effects and no significant differences in mean baseline values for FEV1 or PD20 histamine, methacholine and metabisulphite (table 2).

\section{Change in PEFR during treatment}

There was no significant difference in the change in morning PEFR on ipratropium compared with placebo (-23 versus $\left.-12 \mathrm{~L} \cdot \mathrm{min}^{-1} ; \mathrm{p}<0.4\right)$ (table 3 ) or in PEFR variability measured as amplitude percentage mean on ipratropium and placebo (3.3 versus $0.2 \%$; $<<0.1$ ).

Change in FEV1, PEFR, symptom scores and rimiterol use after cessation of treatment (table 3)

Following cessation of treatment, there was a fall in FEV1 from baseline values after ipratropium and placebo. Although the fall was greater after ipratropium for all four measurements on Days 15 and 16 and greatest in the afternoon of both days, it was only significant in

Table 3. - Change in PEFR during treatment and in FEV1 and PD20 histamine, methacholine and metabisulphate after treatment, with the mean difference $(95 \% \mathrm{Cl})$ between treatments

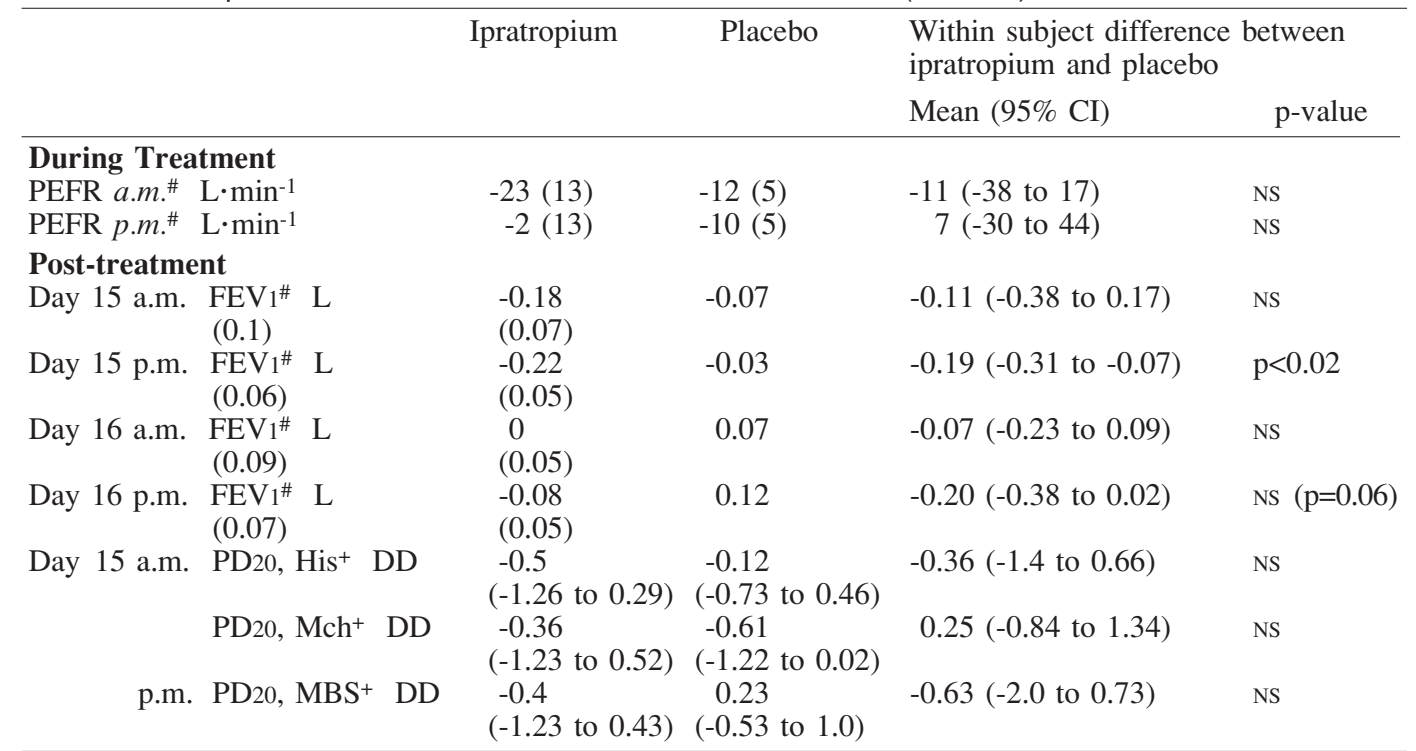

\#: mean, and SEM in parenthesis; +: mean, and 95\% CI in parenthesis. 95\% CI: 95\% confidence interval. DD: doubling doses. NS: nonsignificant. For further definitions see legend to table 1 and 2 . 
the afternoon on Day 15, $30 \mathrm{~h}$ after the last dose of ipratropium (mean difference $-190 \mathrm{~mL} ; 95 \% \mathrm{CI}-310$ to -70 $\mathrm{mL} ; \mathrm{p}<0.02)$. FEV1 had risen when measured 6-10 days after cessation of treatment, and was not significantly different when compared to baseline values after ipratropium or placebo (mean difference $140 \mathrm{~mL}$ higher after ipratropium; 95\% CI 230 to $-51 \mathrm{~mL}$; $\mathrm{p}<0.4$ ).

PEFR on Day 15 (19-37 h after the last dose) was significantly lower after cessation of ipratropium than after placebo (mean difference $4.6 \%$; 95\% CI 1.6-7.5\%; $\mathrm{p}<0.01$ ) but did not differ significantly by Day 16 (mean difference $0.1 \%$; $95 \%$ CI $-3.4-3.6 \%$ ). There were no significant changes in symptom scores or rimiterol use after cessation of treatment.

\section{Change in airway responsiveness}

There was a small fall in PD20 histamine and methacholine on Day 15 both after ipratropium and placebo (table 3) but the differences between treatments were not statistically significant. The difference in PD20 metabisulphite (p.m. Day 15) after ipratropium and placebo was also nonsignificant.

\section{Discussion}

We have compared the airways response during and after 2 weeks of treatment with ipratropium and placebo in subjects with mild asthma. There was a fall in FEV1 from baseline on the two days following cessation of treatment with ipratropium compared to treatment with placebo, which had disappeared 6-10 days later. The reduction in FEV1 was significant $30 \mathrm{~h}$ after cessation of treatment, coinciding with the significant fall in PEFR 19-37 $\mathrm{h}$ after treatment. The maximum difference in FEV1 $(200 \mathrm{~mL})$ was seen in the afternoon on the second day following the final dose. The consistency of these findings and the tendency towards lower PEFR readings in the morning on regular ipratropium treatment suggest that ipratropium is associated with a small reduction in lung function when its bronchodilator effect wears off. There was no significant change in sensitivity to inhaled histamine, methacholine or metabisulphite measured 24, 25 and $30 \mathrm{~h}$ after cessation of treatment, respectively. Although the power of the study was reduced, since four subjects withdrew, this is unlikely to have affected the significance of the PD20 values, since none was close to being statistically significant.

The most likely cause of the fall in lung function following regular treatment with ipratropium is upregulation of muscarinic receptors, causing denervation hypersensitivity. The lack of any significant change in the response to inhaled methacholine or metabisulphite compared to placebo is surprising, therefore, and argues against such a mechanism. Evidence from animal studies suggests that metabisulphite acts through the vagus [14], though this may be partly via nonadrenergic noncholinergic pathways, since the effect of atropine on the bronchoconstrictor response to metabisulphite and $\mathrm{SO}_{2}$, its putative mediator, is variable in man $[11,15]$. Newcomb et al. [6] found a fall in PD20 methacholine of half a doubling dose $24 \mathrm{~h}$ after cessation of 3 weeks of treatment with ipratropium, in an uncontrolled trial. The fall in PD20 methacholine in their study is similar to that seen in our study but we found a similar fall after placebo. In addition, the change in the response to histamine in our study was similar to that for methacholine, which would not have been expected with muscarinic receptor upregulation. Change in FEV1 was not recorded in the study by Newcomb et al. [6]. Muscarinic receptor upregulation might also be expected to cause tolerance to the bronchodilator action of ipratropium, unless the dose of ipratropium is sufficient to block the upregulated receptors. Tolerance to ipratropium has not been examined in a placebo-controlled trial, although tolerance has been shown with inhaled atropine [16].

Other theories to explain the bronchoconstriction seen in our study are more speculative. Methacholine and ipratropium are considered to be nonspecific muscarinic agonist and antagonist, respectively, and would be expected to act on the same population of muscarinic receptors, since both were given by inhalation. Differences in distribution or tissue penetration of ipratropium and methacholine could cause selective upregulation of different muscarinic receptor subtypes and could conceivably account for the fall in FEV1 in the absence of change in PD20 methacholine. Upregulation of ganglionic $\mathrm{M}_{1}$ receptors, for example, would increase endogenous acetylcholine release and cause a fall in FEV1 without necessarily increasing the sensitivity to an inhaled muscarinic stimulus; although it might be expected to increase the response to metabisulphite. It has been suggested that $\mathrm{M}_{2}$ receptors may be dysfunctional in asthma [1] and this could cause them to be less susceptible to upregulation than the facilitatory subtypes $\left(\mathrm{M}_{1}\right.$ and $\left.\mathrm{M}_{3}\right)$; this would increase cholinergic neurotransmission and could account for the bronchoconstriction in our study, though it does not explain why methacholine responsiveness was not increased. Finally, upregulation of muscarinic receptors on airway submucosal glands after ipratropium could cause hypersecretion and worsening airflow obstruction, without an increased response to inhaled muscarinic stimuli.

The design of the present study meant that histamine challenge was followed $1 \mathrm{~h}$ later by methacholine challenge and $6 \mathrm{~h}$ later by metabisulphite challenge; therefore, it is possible that the histamine challenge affected the subsequent methacholine and metabisulphite PD20 values. Most studies have not shown refractoriness following histamine challenge in patients with asthma [17, 18 , although it may occur in subjects with very mild asthma $[19,20]$. Refractoriness to methacholine has not been seen in asthmatic patients [21], so that cross-refractoriness with metabisulphite would not be expected. The order and timing of the challenges was the same for both limbs of the study; therefore, any refractoriness following histamine should not have obscured an effect of ipratropium.

Whatever the underlying mechanism, the present findings may be relevant to the study by VAN SCHAYCK et al. [7], which showed a decline in FEV1 over 2 yrs in subjects with chronic obstructive pulmonary disease given regular, rather than as needed, treatment with salbutamol or ipratropium bromide. They interpreted their findings as a progressive decline in lung function, although the greatest fall in FEV1 was seen at the first measurement 6 months into the study, with more variable change thereafter. 
An alternative explanation for their findings is that they were observing a temporary rebound bronchoconstriction, as they made a single measurement only, at least $8 \mathrm{~h}$ after the last dose of bronchodilator. The fall in FEV1 in the present study $(200 \mathrm{~mL})$ is of the same magnitude as the fall in their study at $2 \mathrm{yrs}$ [7], and is similar in magnitude to the fall in FEV1 seen in several studies following cessation of $\beta$-agonist treatment [22-26]. Whether the rebound effect seen in subjects with asthma in our study is seen in patients with smoking-related airflow obstruction is uncertain, since it was not seen in the Lung Health Study which, unlike the study by vaN SCHAYCK et al. [7], excluded patients with asthma [27]. The results of the present study suggest that the time at which measurements of lung function are made after the last dose of drug may be important in long-term studies of antimuscarinic drugs, such as that by VAN SCHAYCK et al. [7]. It is difficult to judge the clinical significance of these findings but patients who take ipratropium regularly may experience transient deterioration in lung function when they omit or stop treatment.

Acknowledgements: The authors are grateful to S. Pacey for drug randomization and dispensing.

\section{References}

1. Barnes PJ. Muscarinic receptor subtypes in airways. Eur Respir J 1993; 6: 328-331.

2. Takeyasu K, Uchida S, Noguchi Y, et al. Changes in brain muscarinic receptors and behavioral responses to atropine and apomorphine in chronic atropine-treated rats. Life Sci 1979; 25: 585-592.

3. Wise BC, Shoji M, Kuo JF. Decrease or increase in cardiac muscarinic cholinergic receptor number in rats treated with methacholine or atropine. Life Sci 1980; 92: 1136-1141.

4. Hata F, Takeyasu K, Morikawa Y, Lai R, Ishida H, Yoshida H. Specific changes in the cholinergic system in guinea-pig vas deferens after denervation. J Pharmacol Exp Ther 1980; 215: 716-722.

5. Wittenderby PA, Yamamura HI, Halonen M, Palmer JD, Bloom JW. Effects of chronic atropine exposure on airway contraction and muscarinic receptors. Am Rev Respir Dis 1993; 147: A173.

6. Newcomb R, Tashkin DP, Hui KK, Conolly ME, Lee E, Dauphinee B. Rebound hyperresponsiveness to muscarinic stimulation after chronic therapy with an inhaled muscarinic antagonist. Am Rev Respir Dis 1985; 132: 12-15.

7. van Schayck CP, Dompeling E, CLA van Herwaarden, et al. Bronchodilator treatment in moderate asthma or chronic bronchitis: continuous or on demand? A randomised study. BMJ 1991; 303: 1426-1431.

8. Bellingan GJ, Dixon CMS, Ind PW. Inhibition of inhaled metabisulphite-induced bronchoconstriction by inhaled frusemide and ipratropium bromide. Br J Clin Pharmacol 1992; 34: 71-74.

9. Pavord I, Lazarowicz H, Inchley D, Baldwin D, Knox A, Tattersfield A. Cross-refractoriness between sodium metabisulphite and exercise-induced asthma. Thorax 1994; 49: 245-249.
10. Pavord ID, Wong CS, Williams J, Tattersfield AE. Effect of inhaled prostaglandin $\mathrm{E}_{2}$ on allergen-induced asthma. Am Rev Respir Dis 1993; 148: 87-90.

11. Nichol GM, Nix A, Chung KF, Barnes PJ. Characterisation of bronchoconstrictor responses to sodium metabisulphite aerosol in atopic subjects with and without asthma. Thorax 1989; 44: 1009-1014.

12. Tattersfield AE. Effect of beta-agonists and anticholinergic drugs on bronchial reactivity. Am Rev Respir Dis 1987; 136: S64-68.

13. Armitage P. Statistical methods in medical research. Oxford; Blackwell Scientific Publications, 1971.

14. Nadel JA, Salem H, Tokiwa Y. Mechanism of bronchoconstriction during inhalation of sulfur dioxide. $J$ Appl Physiol 1965; 20: 164A.

15. Sheppard D, Wong WS, Uehara CF, Nadel JA, Boushey HA. Lower threshold and greater bronchomotor responsiveness of asthmatic subjects to sulfur dioxide. Am Rev Respir Dis 1980; 122: 873-878.

16. Vaughan TR, Bowen RE, Goodman DL, Weber RW, Nelson HS. The development of subsensitivity to atropine methylnitrate. Am Rev Respir Dis 1988; 138: 771-774.

17. Hariparsad D, Wilson N, Dixon C, Silverman M. Reproducibility of histamine challenge tests in asthmatic children. Thorax 1983; 38: 258-260.

18. Madsen F, H-Rathlou NH, Frolund L, Gerner Svendsen U, Weeke B. Short- and long-term reproducibility of responsiveness to inhaled histamine: $R \mathrm{t}$ compared to FEV1 as measurement of response to challenge. Eur J Respir Dis 1985; 67: 193-203.

19. Manning PJ, Jones GL, O'Byrne PM. Tachyphylaxis to inhaled histamine in asthmatic subjects. $J$ Appl Physiol 1987; 63: 1572-1577.

20. Connolly MJ, Stenton SC, Avery AJ, Walters EH, Hendrick DJ. Refractory period following bronchoconstriction provided by histamine in asthmatic subjects. Thorax 1989; 44: 146-150.

21. Beckett WS, Marenberg ME, Pace PE. Repeated methacholine challenge produces tolerance in normal but not in asthmatic subjects. Chest 1992; 102: 775-779.

22. van Arsdel PP, Schaffrin RM, Rosenblatt J, Sprenkle AC, Altman LC. Evaluation of oral fenoterol in chronic asthmatic patients. Chest 1978; 73: 997-998.

23. Trembath PW, Greenacre JK, Anderson M, et al. Comparison of four weeks, treatment with fenoterol and terbutaline aerosols in adult asthmatics: a double-blind, cross-over study. J Allergy Clin Immunol 1979; 63: 395-400.

24. Harvey JE, Tattersfield AE. Airway response to salbutamol: effect of regular salbutamol inhalation in normal, atopic and asthmatic subjects. Thorax 1982; 37: 280 287.

25. Sears MR, Taylor DR, Print CG, et al. Regular inhaled beta-agonist treatment in bronchial asthma. Lancet 1990; 336: 1391-1396.

26. Wahedna I, Wisniewski A, Wong C, Pavord I, Tattersfield AE. Asthma control during and after cessation of regular beta-agonist treatment. Am Rev Respir Dis 1993; 148: 707-712.

27. Anthonisen NR, Connett JE, Kiley JP, et al. Effects of smoking intervention and the use of an inhaled anticholinergic bronchodilator on the rate of decline of FEV1: the Lung Health Study. JAMA 1994; 272: 1497-1505. 